\title{
MODERNIDADE EXCLUDENTE E PERIFÉRICA: Uma possibilidade de (re)leitura
}

Vitor Azevedo Abou Mourad ${ }^{1}$

\section{RESUMO}

Este artigo tem por objetivo central analisar a Modernidade enquanto uma visão de mundo necessariamente excludente, repleta de paradigmas e uma hierarquia que privilegia uns, em detrimento de outros. Nesse sentido, será assumida, por meio da literatura comparada (CARVALHAL, 2006), uma postura analítica, de caráter solidário (ABDALA JUNIOR, 1996) entre três obras da literatura lusófona: os romances portugueses $A$ cidade e as serras (QUEIROZ, 1901) e A selva (CASTRO, 1938), e o brasileiro Nove Noites (CARVALHO, 2002). Percebem-se, assim, atravessamentos nas obras no que diz respeito à Modernidade e aos seus braços, como o colonialismo (SANTOS, 2007) e a opressão, sobretudo daqueles considerados à margem, na periferia. Para refletir acerca de tais questões, será fundamental compreender os seus imbricamentos, como o papel das cidades nessa ideia de Modernidade (SIMMEL, 1973) e os mecanismos utilizados pelos opressores para se colocarem em um estado de soberania. Tais caminhos confluem, ainda, em aspectos que podem ser pensados à luz do realismo e suas novas facetas (MARGATO, 2009; PELLEGRINI, 2007).

PALAVRAS-CHAVE: modernidade. periferia. colonialismo. literatura lusófona. literatura comparada.

\begin{abstract}
This article aims to analyze Modernity as a necessarily excluding worldview, full of paradigms and a hierarchy that privileges some over others. In this sense, it will be assumed, through comparative literature (CARVALHAL, 2006), an analytical posture, with a solidary point of view (ABDALA JUNIOR, 1996) among three books of Lusophone literature: the Portuguese novels The City and the Mountains (QUEIROZ, 1901) and The Jungle (CASTRO, 1938), and the Brazilian Nine Nights (CARVALHO, 2002). Thus, crossings can be seen in the works with regard to Modernity and its arms, such as colonialism (SANTOS, 2007) and oppression, especially those considered on the margins, on the periphery. To reflect on these issues, it will be essential to understand their overlaps, such as the role of cities in this idea of Modernity (SIMMEL, 1973) and the mechanisms used by oppressors to place themselves in a state of sovereignty. Such paths also converge in aspects that can be thought of in the light of realism and its new facets (MARGATO, 2009; PELLEGRINI, 2007).
\end{abstract}

KEY WORDS: modernity. periphery. colonialism. lusophone literature. comparative literature.

\section{Considerações iniciais}

A literatura lusófona é, de fato, uma das mais ricas mundialmente, em termos de quantidade e de qualidade. Afinal, não são apenas Portugal e Brasil os países falantes da Língua Portuguesa. Atualmente, oito nações integram a Comunidade dos Países da Língua Portuguesa (CPLP) e são responsáveis pela disseminação de sua literatura. Entretanto, essa literatura não foi construída alheia aos elementos externos, mas sim a partir da confluência e da integração entre diversos povos, falantes ou não da mesma língua. Assim, a literatura lusófona é fruto de um forte e cruel processo de colonização que, em alguns países, chegou a durar até a segunda metade do século XX.

\footnotetext{
${ }^{1}$ Licenciando em Letras - Língua Portuguesa e Respectivas Literaturas (PUC-Rio).
} 
Diante dessa situação, Benjamin Abdala Junior (1996) desenvolveu o conceito de comparatismo da solidariedade, que, opondo-se ao comparatismo da necessidade - que considera que as literaturas de países mais ricos influenciam as dos países subdesenvolvidos, que as imitam - admite as diferentes literaturas em um mesmo nível, sem estabelecer relações de superioridade de um texto em relação a outro. Em relação à literatura comparada, Tânia Franco Carvalhal defende a ideia de que todo texto é fruto da leitura de outros textos, existindo, portanto, um diálogo contínuo entre eles. Para ela, a literatura comparada

\begin{abstract}
compara não pelo procedimento em si, mas porque, como recurso analítico e interpretativo, a comparação possibilita a esse tipo de estudo literário uma exploração adequada de seus campos de trabalho e o alcance dos objetivos a que se propõe. Em síntese, a comparação, mesmo nos estudos comparados, é um meio, não um fim. (CARVALHAL, 2006, p. 7)
\end{abstract}

Ademais, a literatura comparada ocupa-se de diversos aspectos, interagindo também com outras áreas, como a crítica, a historiografia e a teoria literárias. Dentre seus principais objetivos, está a "elucidação de questões literárias que exijam perspectivas amplas" (CARVALHAL, 2006, p. 86), diferentes ou próximas, contribuindo para a formação do pensamento crítico e reflexivo de seus leitores.

Tomando como base os estudos e paradigmas da literatura comparada, este trabalho objetiva, por meio do comparatismo de solidariedade, analisar como o conceito de Modernidade foi e ainda é construído, pensando, também, como podemos compreendê-la como excludente, a partir da análise de romances que se atravessam pelos impactos do colonialismo e pela língua portuguesa, mesmo com suas diferenças e variações.

\title{
2. Pensando a Modernidade
}

Ao longo dos anos, o conceito de Modernidade foi sofrendo alterações, abrindo espaço para outras interpretações, além da mais conhecida, a de Modernidade enquanto condição histórica, assim como outras como a Medieval e a Antiga. Nessa forma de entendimento, ela é uma consequência do Iluminismo e dos movimentos revolucionários, como a Revolução Francesa, que marca, justamente, a Era Moderna. Não por coincidência, a presença do povo está marcada na Modernidade, pois as revoluções abriram mais espaço para esse tipo de movimento. Há, ainda, o crescimento do ramo tecnológico, o que impulsiona essa postura de história.

Outra possibilidade em relação à interpretação da Modernidade é enxergá-la como uma visão de mundo, ou seja, uma forma de perceber e a analisar o que acontece nas relações humanas e naturais. Essa concepção, levada em conta neste estudo, possui algumas 
características marcantes. O primeiro traço da Modernidade enquanto visão de mundo é a hierarquia de valores. Há uma tentativa forte de rompimento com o velho, considerado obsoleto. Assim, busca-se atingir o novo. Consequentemente, alguns valores e saberes são considerados superiores a outros, ocorrendo uma comparação notória entre eles.

Ademais, o progresso configura-se como um elemento crucial nessa Modernidade, entendido como algo permanente, que não tem volta, e que é o ponto-chave da Modernidade, com a ideia de que o futuro sempre será melhor do que o passado. Outrossim, a cidade é considerada um grande sinal do progresso, sobretudo a metrópole, bastante estudada pelo sociólogo alemão Georg Simmel, que buscava relacioná-la à vida mental dos indivíduos. Ele defendia que a "base psicológica do tipo metropolitano de individualidade consiste na intensificação dos estímulos nervosos, que resulta da alteração brusca e ininterrupta entre estímulos exteriores e interiores." (SIMMEL, 1973, p. 12).

Com essa intensificação e a aceleração da vida cotidiana, algumas consequências necessárias são geradas, como a especialização dos indivíduos, diante das condições de trabalho e convívio. Por conseguinte,

\footnotetext{
essa especialização torna um indivíduo incomparável a outro e cada um deles indispensável na medida mais alta possível. Entretanto, esta mesma especialização torna cada homem proporcionalmente mais dependente de forma direta das atividades suplementares de todos os outros. (SIMMEL, 1973, p. 11)
}

Dessa maneira, entende-se que, ao promover uma uniformização, a Modernidade retira, de certa maneira, a identidade individual das pessoas. Ocorre, então, um processo de exclusão, de perda, que é mais uma marca da Modernidade estudada aqui, sendo, portanto, excludente e, por consequência, periférica. Assim, “"parece que a modernidade ocidental só poderá expandirse globalmente na medida em que viole todos os princípios sobre os quais fez assentar a legitimidade histórica do paradigma da regulação/emancipação deste lado da linha." (SANTOS, 2007, p. 15). Seguindo essa linha de pensamento, Boaventura de Sousa Santos (2007), passando pelo pensamento abissal, desenvolve a importância de uma ecologia dos saberes.

Nessa direção, destaca-se o colonialismo como um braço da Modernidade, pautada na ocupação violenta de territórios e de corpos, como demonstra o português Ferreira de Castro em seu romance A selva (1945) e o brasileiro Bernardo Carvalho no seu Nove Noites (2006), mesmo se tratando de outra época histórica. A discussão em torno da metrópole e do progresso aparece ainda em A cidade e as serras (2018), do português Eça de Queirós. 
Percebe-se, portanto, que esses autores, mesmo sendo de países diferentes, traçam em sua literatura as marcas da modernidade enquanto uma visão de mundo que exclui, que afasta e que é repleta de paradigmas e questões a serem desenvolvidos.

\section{Campo e cidade em constante oposição}

Com a Modernidade, aumentou-se a dicotomia campo-cidade, considerando o campo como um sinal de retrocesso e a cidade como um espaço de desenvolvimento e progresso. Assim, no ambiente rural,

o ritmo da vida e do conjunto sensorial de imagens mentais flui mais lentamente, de
modo mais habitual e mais uniforme. É precisamente nesta conexão que o caráter
sofisticado da vida psíquica metropolitana se torna compreensível - enquanto
oposição à vida de pequena cidade, que descansa mais sobre relacionamentos
profundamente sentidos e emocionais. (SIMMEL, 1973, p. 12).

Simmel preocupou-se em estabelecer uma relação entre a metrópole e a vida mental dos indivíduos, partindo da intensificação dos estímulos nervosos. Dessa maneira, uma diferença inicial entre os indivíduos do campo e os da cidade residiria na consciência exigida por cada ambiente. Essa oposição serve como pano de fundo para o romance A cidade e as serras (2018), de Eça de Queirós. Porém, “mais do que uma polarização entre a cidade e o campo, a obra apresenta-nos uma discussão: o que fazer frente a uma burguesia cujo valor supremo é o dinheiro e ao que por ele é adquirido?'” (FARIA. In: QUEIROZ, 2018, prefácio).

Publicado em 1901, um ano após a morte do autor, A cidade e as serras traz uma questão extremamente importante e ainda muito atual, o culto à tecnologia. Na obra, Zé Fernandes narra a história de seu amigo Jacinto, um defensor ferrenho das cidades e no poder do homem civilizado e que mora na Avenida dos Campos Elísios, a famosa Champs-Élysées, no centro parisiense. Já o narrador acredita que a vida no campo é superior à vida na cidade e mora em Guiães, nas serras portuguesas.

Trazendo para o romance assuntos presentes na vida das pessoas, como a questão tecnológica, Eça desenvolve seu olhar realista. Esse movimento “desde o início negou que a arte estivesse voltada apenas para si mesma ou que representar fosse apenas um ato ilusório, debruçando-se agora sobre as questões concretas da vida das pessoas comuns, representadas na sua prosaica tragicidade'”. (PELLEGRINI, 2007, p. 140).

Essa forma de representar relaciona-se diretamente ao livro $A$ cidade e as serras, pois ele tem como eixo central a fórmula criada por Jacinto e apresentada logo no primeiro capítulo: “'Suma Ciência X Suma Potência = Suma Felicidade” (QUEIROZ, 2018, p. 18). A partir dessa fórmula, criticada por Zé Fernandes, ele irá desenvolver todo um relato para mostrar por que 
acredita que essa fórmula é equivocada. Já em uma das primeiras páginas deste capítulo, o narrador afirma: " nem eu percebia que vantagem espiritual ou temporal se colha em distinguir através do espaço manchas num astro, ou através da avenida dos Campos Elísios presuntos numa vidraça", (QUEIROZ, 2018, p. 19). É possível reparar a opinião contrária de Zé Fernandes em relação à de Jacinto, tendo em vista que o primeiro não acredita que uma pessoa pode ser mais feliz do que outra devido à ciência e à potência.

Mas o que seriam a Suma Ciência e a Suma Potência? A primeira reúne a tecnologia, tão discutida na obra, e o clássico, itens muito valorizados por Jacinto, mas que, como Zé Fernandes prova, são falhos, não tendo funcionamento pleno e eficaz. Já a segunda corresponde aos problemas filosóficos enfrentados por Jacinto, que, como apontado pelo empregado Grilo, estava insatisfeito com a sua vida, pois esperava que a tecnologia pudesse lhe fornecer bastante felicidade, o que, na realidade, não ocorreu.

As diferenças entre campo e cidade expandem-se, na obra, à questão econômica, apresentando também um conflito entre a elite e a classe trabalhadora. Isso pode ser percebido observando os próprios protagonistas. Jacinto, como descrito no primeiro capítulo, é de família nobre, nascido num palácio, um fidalgo, enquanto Zé Fernandes vem de uma família rural, de trabalhadores. Após anos afastados, depois da faculdade, os dois se reencontram, em Paris, aonde Zé vai, buscando descansar e rever o amigo.

Zé Fernandes depara-se com um Jacinto diferente, muito infeliz, apesar de ter todas as tecnologias possíveis em sua residência, algo extremamente importante para ele. É aí que surge uma questão fundamental nesse livro: o valor do dinheiro. Com ele, Jacinto conseguiu realizar seu desejo de ser um "'homem civilizado", dispondo de diversas tecnologias, além dos muitos livros, mas sua vida tornou-se superficial, com amizades falsas e os livros, em vez de the trazer prazer e entretenimento, causavam irritação. Quando vai ao ambiente rural, com Zé Fernandes, Jacinto experimenta um espaço muito diferente da movimentada Paris, no auge de sua industrialização. A comida de Guiães é um dos elementos que se torna especial para ele, como destacado no décimo segundo capítulo.

Com efeito, é possível compreender o dinheiro como grande influenciador da personalidade dos indivíduos, moldando seus comportamentos. Segundo Simmel (1973), o dinheiro reduz a qualidade e a individualidade de cada pessoa a uma questão: quanto?. Ele ainda afirma que as relações emocionais surgem dessa individualidade tão renegada, enquanto as relações racionais, ao contrário, entendem os seres como números, ou seja, abandonando sua identidade e particularidade. Logo, percebe-se, em "As cidades e as serras", que a 
personalidade de Jacinto é completamente reduzida, vindo a ter uma ressignificação apenas quando ela faz uma visita à serra, junto de Zé Fernandes.

Outra questão de suma importância na obra é a relação entre a ciência e a ideia de Modernidade pregada por Jacinto. Ideia essa que coloca a Modernidade acima de valores e saberes antigos, ou seja, sobrepondo-se à tradição e revelando, assim, uma suposta superioridade da cidade em relação ao campo e, consequentemente, de Paris em relação a Portugal. É válido ressaltar que a Modernidade deve ser enxergada como uma visão de mundo necessariamente excludente, centrada no progresso e no desenvolvimento, e não apenas uma condição histórica. Ela é, portanto, paradoxal, já que une e, ao mesmo tempo, afasta, significando "a coexistência de sociedade civil e estado de natureza separados por uma linha abissal com base na qual o olhar hegemônico, localizado na sociedade civil, deixa de ver e declara efetivamente como não-existente o estado de natureza.” (SANTOS, 2007, p. 8).

Contudo, a ideia de ciência trazida, como visto anteriormente no termo "Suma ciência', não é tão ampla como defendem alguns estudiosos. Se esses consideram ciência como um conhecimento aprofundado, no romance de Eça de Queirós e para muitos na mesma época, o entendimento é totalmente outro. Apenas era ciência o que fazia parte do ramo natural ou tecnológico. Assim, as ciências humanas, as da linguagem e muitas outras não eram consideradas. Logo, a ciência é tida como uma força propulsora da ideia de Modernidade excludente, que despreza alguns saberes. Simmel ainda revela os motivos de certos ideais serem tão valorizados: “Pontualidade, calculabilidade, exatidão, são introduzidas à força na vida pela complexidade e extensão da existência metropolitana e não estão apenas muito intimamente ligadas à sua economia do dinheiro e caráter intelectualístico.” (SIMMEL, 1973, p. 15).

Posteriormente, a partir da metade do século XX, houve uma mudança nesse cenário, alterando a relação entre crenças e ideias, que

deixa de ser uma relação entre duas entidades distintas para passar a ser uma relação
entre duas formas de experienciar socialmente a ciência. Esta dualidade faz com que
o reconhecimento da diversidade cultural do mundo não signifique necessariamente o
reconhecimento da diversidade epistemológica do mundo. (SANTOS, 2007, p. 24)

Partindo disso, entende-se que “as profundas diferenças entre saberes levantam a questão da incomensurabilidade, uma questão utilizada pela epistemologia abissal para desacreditar a mera possibilidade de uma ecologia de saberes.' (SANTOS, 2007, p. 30). Nessa direção, é possível perceber a importância de todos os conhecimentos e a ecologia dos saberes como uma alternativa possível e muito coerente neste contexto.

Outrossim, Eça de Queirós tece diversas críticas aos costumes culturais e políticos de seu país, conhecidos popularmente como "portugalidade", aproveitando-se do realismo de 
espelho, ou seja, que buscava espelhar a sociedade, para trazer mensagens irônicas e também de desesperança quanto a Portugal.

Tal pensamento sobre a suposta superioridade urbana exclui o fato de que a cidade e o campo não são campos monolíticos, podendo estar um dentro do outro. Ademais, a visão que os moradores das serras têm em relação a Jacinto é formada por influência desse pensamento que prioriza o dinheiro, visto que rejeitam o parisiense por ligá-lo a Dom Miguel, conhecido como "o Absolutista" e “o Tradicionalista”. Em passagens do décimo terceiro capítulo, percebe-se tal associação e a resposta de Jacinto:

\footnotetext{
- Pois sabe mais, meu pobre amigo. Todos pensam o mesmo, estão desconfiados, e receiam ver de novo erguidas as forças em Guiães! E corre que tu tens o Príncipe D. Miguel escondido em Tormes, disfarçado em criado. (...) Vou ter aqui bons amigos, quando verificarem que não sou miguelista. (...) Eu, minha senhora, sou socialista... (QUEIROZ, 2018, p. 194)
}

Esses fragmentos reforçam a visão que a população do ambiente rural tinha em relação aos habitantes das cidades, relacionando-os, imediatamente, a um imperador absolutista.

Por conseguinte, a mudança da visão de Jacinto em relação ao campo e à vida agitada da cidade só começa a mudar quando ele vai às serras portuguesas, porque, percebendo toda a grandeza e a beleza da natureza da serra, ele percebe que estava deveras alienado e preso à vida repetitiva e agitada da cidade de Paris. Já no último capítulo, Jacinto afirma: “A serra, Deus louvado, prospera. E agora, para cima! Tu hoje ficas em Tormes. Para contar da Civilização.' (QUEIROZ, 2018, p. 216). Nota-se, aqui, a ideia citada anteriormente de que há ilhas do campo na cidade e ilhas da cidade no campo, sendo impossível, dessa maneira, a cidade excluir por completo o atraso, tão atribuído ao campo.

\section{Os submundos do colonialismo}

A Modernidade, nessa visão de exclusão e periferia, relaciona-se diretamente com o colonialismo e as suas heranças para as sociedades. O colonialismo pode ser considerado um braço violento da Modernidade, responsável por chegar à periferia. Ele, ainda, foi pautado na ocupação violenta de territórios em busca da manutenção da riqueza europeia, como é o caso do próprio Brasil, tão explorado em setores, como o do pau-brasil e o da mineração, mesmo com a enorme diferença entre os anos de cada um desses momentos. Dessa forma, vislumbrase uma distinção invisível, que é

a distinção entre as sociedades metropolitanas e os territórios coloniais. De facto, a dicotomia regulação/emancipação apenas se aplica a sociedades metropolitanas. Seria impensável aplicá-la aos territórios coloniais. Nestes aplica-se uma outra dicotomia, a dicotomia apropriação/violência que, por seu turno, seria inconcebível aplicar deste lado da linha. (SANTOS, 2007, p. 4) 
Pelas palavras de Boaventura de Sousa Santos, nota-se a crueldade e violência do processo colonial, no geral, marcado também pela exploração de pessoas, em regimes de escravidão ou análogos a ela. Toda essa situação ligada a uma noção de Modernidade bruta em relação ao colonial pode ser verificada no romance $A$ selva, lançado em 1930, escrito pelo português Ferreiro de Castro.

Esse romance, ao mesmo tempo, se aproxima e se distancia de $A$ cidade e as serras no que diz respeito à Modernidade. A obra conta a história de Alberto, um jovem português que, devido a suas ideias políticas, sai do seu país e vai em direção a Belém do Pará. A expectativa em relação à viagem é grande, pois se acredita que ela pode trazer muito dinheiro, o que pode ser comprovado na fala do personagem Macedo, tio de Alberto, presente no primeiro capítulo: “ Olha que eu tenho visto muita gente embarcar nas tuas condições e voltar lá em cima, pôdre de rico". (CASTRO, 1945, p. 31).

Entretanto, as pessoas que embarcam ali em Portugal, no Justo Chermont, rumo ao Brasil, não imaginavam as reais condições de trabalho, com a exploração dos trabalhadores nos seringais. Chegando a terras brasileiras, deparam-se com uma situação completamente degradante, além de uma grande dívida, oriunda de outras “despesas" do trabalhador, como o transporte. Esse regime de trabalho seria, portanto, um submundo do colonialismo, uma obscuridade, principalmente quando se refere a uma sociedade pós-abolição da escravidão, que deveria, teoricamente, não ter mais esse tipo de prática.

É possível enxergar, nessa abordagem, traços fortes do realismo, pois ele

faz da realidade física e social (no sentido materialista do termo) a base sobre a qual se assentam o pensamento, a cultura e a literatura. Aceitar, desse modo, que a literatura esteja voltada apenas para si mesma ou que nada se 'representa' além do próprio texto é escamotear a própria ideia de representação, num jogo auto-reflexivo em que o objeto representado desaparece. (PELLEGRINI, 2007, p. 140)

Estabelecendo um paralelo entre as palavras de Pellegrini e o texto de Ferreira de Castro, é possível compreender que esse utiliza a realidade histórica, de exploração para construir sua história e seus pensamentos. Trata-se, logo, de uma representação e, sobretudo, uma denúncia das condições na Amazônia, o que foi algo de grande importância, pois se tratava um escritor português expondo essa dura conjuntura.

Além do trabalho, uma surpresa para Alberto e os demais é a periculosidade da região, devido aos índios, considerados violentos. São contadas histórias fortes a respeito da relação entre o "homem branco" e o indígena, como a de que os nativos "levam sempre a cabeça dos civilisados. É para espetar num páu e dansar á volta dela. Fazem uma festa para provar que ganharam e que são valentes'”. (CASTRO, 1945, p. 102-103). Percebe-se, então, que se trata 
de uma disputa de poder. Já que os civilizados invadiram a terra dos índios, mostrando, aí, uma superioridade, um poder maior, os nativos decidem agir violentamente contra os brancos, para mostrar também a sua força e que eles, dificilmente, aceitarão submissão. Mais adiante no romance, Alberto encara frente a frente essa situação: “Lá estava um homem sem cabeça e outro, vermelhusco, latagão, de longo e lusidio cabelo, como Alberto nunca vira'. (CASTRO, 1945, p. 243).

Atrelado a essa imagem, percebe-se também, na obra, o nítido retrato preconceituoso, carregado de visões pré-concebidas, a respeito das populações nativas da Amazônia. Quando o Justo Chermont aproxima-se de uma área habitada, o narrador descreve as pessoas como “vultos humanos", e a aparência delas: “Distinguia-se agora a côr dos que estavam em terra: os pretos e os multados, a blusa de riscado, as calças de brim azul, o largo chapeirão de carnaúba e os pés descalços ou enfiados nuns sapatos estranhos'”. (CASTRO, 1945, p. 75). Revela-se, aqui, mais um traço do colonialismo: a ideia de superioridade do colonizador, neste caso, dos detentores de maior poder, diante do negro, colocado em posição de inferioridade, que se repete, capítulos depois, quando um índio é encontrado morto: “Índio em cova de cristão? É melhor deitar o bicho ao rio, para as piranhas jantarem...' (CASTRO, 1945, p. 243).

Todavia, não apenas os índios são vistos na obra de Ferreira de Castro sob uma perspectiva preconceituosa, mas também outras populações de minoria e marginalidade: " $\mathrm{O}$ negro Tiago, que fôra escravo e, agora, era quási inútil (...) A selva acolhia com espanto aquela vez e ia-a repercutindo de desvão e desvão.’'(CASTRO, 1945, p. 195).

Nota-se, nesse fragmento, outro aspecto de suma relevância no texto: o papel da selva. O narrador a coloca como sujeito de ações, atuando como agente, até em casos de personificação: “A selva começou a falar no olvido da noite. Surgiram, por tôda a parte, vozes estranhas e imprecisa', (CASTRO, 1945, p. 92). No romance, a selva ganha tanta importância que chega a se tornar uma personagem da história, tendo como grandes marcas o mistério e a opressão: “A tristeza brotava desse vêrde eterno e sempre igual, que oprimia, que sufocava com a sua pertinácia e exuberância.'” (CASTRO, 1945, p. 176).

Opondo-se à imagem da selva, da floresta, existe a da cidade, questão tão discutida no romance de Eça de Queirós e que aparece também aqui, demonstrando o deslumbramento dos navegantes ao chegar em Manaus, uma cidade, naquela época, já mais desenvolvida em relação às demais amazonenses: “Manáus era um clarão radioso na noite amazonense”. (CASTRO, 1945, p. 56). Nesta obra, a cidade relaciona-se bastante à divisão do trabalho, uma marca do cânone neorrealista, ao lado de outros pontos, como as classes sociais e a exploração do homem pelo próprio homem, mencionados anteriormente. Há, no romance, uma clara divisão do 
trabalho, destinando o ofício mais árduo às pessoas deixadas à margem, periféricas, como os estrangeiros, sem nem considerar a sua formação, como foi o caso de Aberto, em boa parte do livro. À medida que vai se expandindo, "a cidade oferece mais e mais as condições decisivas da divisão de trabalhos. Oferece um círculo que, através de seu trabalho, pode absorver uma variedade altamente diversificada de serviços"'. (SIMMEL, 1973, p. 21-22).

Neste espaço de exploração e desvalorização total dos direitos humanos, é importante destacar a importância e o poder dos bens materiais, em especial, o dinheiro, pois ele, "com toda sua ausência de cor e indiferença, torna-se o denominador comum de todos os valores; arranca irreparavelmente a essência das coisas, sua individualidade, seu valor específico e sua incomparabilidade.' (SIMMEL, 1973, p. 16). Isso se percebe no romance de Ferreira de Castro em diversos momentos, como os momentos em que é discutido o valor de cada empregado, o custo e o retorno que dão, em serviço. Com esse motivo é explicada a ausência das mulheres: " 'O que seu Juca quer é seringueiro sozinho, que trabalha muito para tirar saldo e ir ver a mulher ou casar lá no Ceará.' (CASTRO, 1945, p. 129).

O trabalho com a seringueira é muito valorizado devido à sua lucratividade, mas, ao passar do romance, essa atividade vai perdendo forças: "A borracha entrara em declive, descendo cada vez mais, e o verão, abrindo de novo as trilhas da selva, não trouxera aos seringueiros nenhum calor de estímulo', (CASTRO, 1945, p. 177). Com isso, por volta do décimo quarto capítulo, narra-se que uma alternativa para salvar essa atividade tão tradicional e importante economicamente acaba sendo a chegada de estrangeiros, como os japoneses.

Ao final do livro, o incêndio, ocasionado por Tiago, é uma maneira de libertação, uma tentativa de acabar com o sistema e, sobretudo, com as agressões. Tiago faz isso, fechando ainda as portas para que Juca não conseguisse sair, já que ele também sofreu algo semelhante quando morava ainda no Maranhão, no tronco. Nas palavras do próprio Tiago: “Mas seu Juca se desviou... Estava a escravizar os seringueiros. Tronco e peixe-boi no lombo só nas senzalas. E já não há escravatura...' (CASTRO, 1945, p. 297).

Os elementos que ganham espaço no texto, portanto, fazem dele uma obra neorrealista, devido também à forma como são feitos a abordagem e o tratamento. Anticapitalismo, temática social e histórica, luta de classes, objetividade e personagens vulgares são apenas algumas características dessa corrente artística, que se destaca a partir da década de 1930, tanto em Portugal quanto no Brasil e em outros países. Esse movimento resgatou valores do realismo e do naturalismo, como a analogia entre homem e animal, além de muitos elementos em comum também com o modernismo e a psicanálise. Ademais, 
a famosa e linear assertiva: "a redução do artístico ao ideológico", usada para definir as obras neo-realistas, é o grande argumento escolhido por todos aqueles que se colocam em posição de reserva, ou mesmo de firme oposição, a movimento. Mais precisamente, essa assertiva foi o grande fantasma com que tiveram que se debater todos aqueles que aceitaram a súbita exigência de produzir arte e, ao mesmo tempo, centrar o seu interesse no estudo da sociedade. Este é, enfim, o grande lugar-comum que polariza, interna e externamente, a polêmica em torno da arte neo-realista. (MARGATO, 2009, p. 45-46)

Dessa maneira, considerando essa assertiva, toda a história do livro, a arte, se reduziria ao ideológico. Entretanto, o neorrealismo vai além disso. Ele foca em denunciar e intervir social e humanitariamente, mostrando a realidade sem filtros, como ela é. Assim, Ferreira de Castro cumpre muito bem sua função neorrealista em $A$ selva, através dessa viagem à Amazônia, uma viagem moral e subjetiva.

\section{O silenciamento das minorias}

Além da colonialidade e do conflito entre espaços rural e urbano, outra marca da Modernidade periférica é a ausência de voz e, consequentemente, de espaço das populações vistas como minoritárias, mas que, algumas vezes, são maioria dentro de um espaço, submetendo-se às ordens de uma minoria detentora do poder. Nessa direção, essas populações, tão segregadas, são caladas, em diversos âmbitos, como o social, o político e o midiático. Relacionados a esse contexto estão os conceitos de apropriação e violência. $\mathrm{Na}$ área do conhecimento,

a apropriação vai desde o uso de habitantes locais como guias e de mitos e cerimónias locais como instrumentos de conversão, à pilhagem de conhecimentos indígenas sobre a biodiversidade, enquanto a violência é exercida através da proibição do uso das línguas próprias em espaços públicos, da adopção forçada de nomes cristãos, da conversão e destruição de símbolos e lugares de culto, e de todas as formas de discriminação cultural e racial. (SANTOS, 2007, p. 9)

Fica claro, portanto, que a apropriação se relaciona a uma incorporação, enquanto a violência é uma destruição, que pode ser moral, material, cultural e física. No que se refere ao silenciamento das ditas minorias, é possível perceber uma ação conjunta de apropriação e de violência. O colonizador apropria-se dos nativos para, depois, convertê-los, praticando, aí, a destruição da terra, a natureza, das memórias, da cultura e também de vidas. É importante destacar também a heterogeneidade das populações nativas, sobretudo as indígenas. O termo “índio" acaba por homogeneizar essa comunidade tão extensa e diversa entre si.

Essa discussão a respeito das populações indígenas e o seu silenciamento está presente no romance Nove Noites, escrito pelo carioca Bernardo Carvalho e lançado em 2002. Ele parte da morte do jovem antropólogo americano Buell Quain, aos 27 anos, por suicídio, enquanto tentava voltar à cidade grande, saindo de uma aldeia indígena no interior do Brasil, os Krahô. 
Trata-se de um caso real, ocorrido em agosto de 1939, e logo esquecido, tornando-se um grande mistério, um ponto de interrogação. O narrador do livro, sessenta e dois anos depois do fatídico dia, fica sabendo da história por acaso, em um artigo de jornal, e decide investigá-la com afinco. Durante toda a obra, ele vai atrás de informações e de pessoas que possam o ajudar, viajando dentro e fora do Brasil na busca de arquivos: " Nada dependeu de mim, mas de uma combinação de acasos e esforços que teve início no dia em que li, para o meu espanto, o artigo da antropóloga no jornal'”. (CARVALHO, 2006, p. 12).

Essa voz, porém, não é a única que narra essa história. Alguns capítulos são contados, com a fonte da letra em itálico, por Manoel Perna, engenheiro sertanejo, que convive com Quain durante nove noites durante seu período no Brasil. Com esse personagem fíctício, Bernardo Carvalho mistura ficção e realidade, criando dados e informações novas nesta história real do antropólogo Quain. Logo no início do romance, Manoel Perna dirige-se, em um testamento, a uma pessoa, que o leitor desconhece, passando conselhos a ela sobre sua ida à aldeia dos Krahô. O primeiro conselho diz respeito à confiança:

Vai entrar numa terra em que a verdade e a mentira não têm mais os sentidos que o
trouxeram até aqui. Pergunte aos índios. Qualquer coisa. O que primeiro lhe passar
pela cabeça. E amanhã, ao acordar; faça de novo a mesma pergunta. E depois de
amanhã, mais uma vez. Sempre a mesma pergunta. E a cada dia receberá uma resposta
diferente. A verdade está perdida entre todas as contradições e disparates.
(CARVALHO, 2006, p. 6)

Percebe-se que os Krahô utilizavam esse método de responder uma coisa diferente a cada dia como uma forma de defesa, sem revelar tudo o que poderiam. Isso porque não confiavam nas pessoas de fora. A visão contrária, dos índios como seres em que não se pode confiar, fica clara também na obra, restringindo aos indígenas o papel de objeto de estudo.

Tal ideia de não contar tudo relaciona-se diretamente ao estilo de narrativa proposto por Bernardo Carvalho, com diversas lacunas, afastando-se de uma visão moderna de narrativa, já que não apresenta grande encadeamento causal dos fatos, mas sim versões, possibilidades, o "fundo falso, "papéis dobrados"”. (PELLEGRINI, 2007, p. 153). Por esse motivo, são levantadas muitas hipóteses em relação à morte de Buell Quain, tanto cogitando ser um homicídio quanto apontando possíveis causas do suicídio.

Outrossim, como apontado anteriormente, Santos (2007), ao trazer a distinção entre apropriação e violência, carrega a última de um sentido de retirada, destruição de elementos. Nesse contexto, uma violência muito marcada no romance de Bernardo Carvalho e vista também na obra de Ferreira de Castro, A selva, é a exploração do meio ambiente, causando a destruição não apenas biológica, mas também humana e cultural às pessoas originárias desse meio: 
Não só pagou uma ninharia pelas terras, como passou a receber subsídios para o projeto agropecuário que implantou a partir de 1970. A prática foi estabelecida como programa pelo governo militar, que sob o pretexto de desenvolvimento na Amazônia não só subvencionou a compra de centenas de milhares de alqueires a preço de banana, como em seguida financiou nababescamente os projetos de ocupação pelos fazendeiros. (CARVALHO, 2006, p. 57-58)

Essa abordagem, expondo o que de fato ocorreu, alinha-se ao realismo contemporâneo, compreendido, aqui, como um “'recurso narrativo rico e renovável, necessário à expressão de uma singularidade social e cultural de bases próprias que, no momento presente, emerge do terreno propício adubado pela urgência e necessidade históricas nacionais'. (PELLEGRINI, 2007, p. 153).

Tal entendimento é o mesmo quando o autor traz outra violência muito pertinente socialmente e destacada em sua obra: a violência contra as populações consideradas inferiores, como as indígenas. Elas sofrem com a perda de traços próprios delas e, consequentemente, de parte de sua identidade. Em Nove Noites, isso se mostra em diversos momentos e tipos. A violência física era absolutamente proibida entre os Krahô, "sobretudo contra as crianças, e Quain por duas vezes quase desencadeou uma comoção social ao bater na mão de um menino que lhe roubava farinha e ao pisar sem querer no pé do outro.' (CARVALHO, 2006, p. 48).

A violência no seu sentido de destruição e perda, no romance, está intimamente vinculada, como já mencionado, à visão tida pelos brancos em relação às comunidades tradicionais. A própria visão de Quain sobre Trumai inicia-se muito carregada de imagens préconcebidas, preconceitos até a construção de sua própria visão, a partir do contato mais próximo, íntimo: “'O fato é que no começo Quain achou os Trumai 'chatos e sujos' ('Essa gente está entediada e não sabe'), o contrário dos nativos com quem convivera em Fiji e que transformara num modelo de reserva e dignidade.' (CARVALHO, 2006, p. 48)

Com os Krahô percebe-se algo semelhante, com uma rejeição da comunidade em relação ao trabalho desempenhado ali pelo antropólogo, como relatado por ele numa carta enviada a Margaret Mead, também antropóloga americana:

\begin{abstract}
A única forma de me impor a eles é ficando bravo, e então, por vinte e quatro horas, tenho todos os duzentos e dez deles aos meus pés, tentando desajeitadamente me satisfazer. Eles ignoram a ideia de se esforçar para ganhar ou receber alguma coisa, já que de hábito podem ganhar muito mais quando ficam emburrados. Venho trabalhando no último mês com um jovem (que é definitivamente um anormal, já que parece gostar de trabalhar comigo). Hoje ele me comunicou que não pode mais trabalhar, pois está cheio de ser ridicularizado pelo resto da aldeia. (CARVALHO, 2006, p. 96-97)
\end{abstract}

Nesse fragmento, é notória a dificuldade de Quain em trabalhar com os Krahô, tendo que recorrer a um comportamento mais autoritário, mas que não fornece tantos resultados, devido ao pouco empenho dos participantes. Dessa maneira, justifica-se um certo afastamento 
do etnólogo, já que ele "não comia com os índios e não aceitava a comida deles. Não comia beiju. Tinha o seu próprio arroz. Uma vez, ajudou num parto, deu nome ao recém-nascido e trouxe presentes. Mas não costumava participar de nada.' (CARVALHO, 2006, p. 73).

Ademais, a visão ainda muito vinculada aos exemplos do hemisfério Norte permanece com o narrador, o investigador, pesquisador, que enxerga uma dependência maior dos indígenas em relação aos brancos do que ao vice-versa, relacionando os primeiros a uma situação de abandono:

São órfãos da civilização. Estão abandonados. Precisam de alianças no mundo dos brancos, um mundo que eles tentam entender com esforço e em geral em vão. $\mathrm{O}$ problema é que a relação de adoção mútua já nasce desequilibrada, uma vez que a frequência com que os Krahô vêm aos brancos é muito maior com que os brancos vão aos Krahô. Uma vez que o mundo é dos brancos. Há neles uma carência irreparável. Não querem ser esquecidos. (CARVALHO, 2006, p. 97)

Nota-se, aqui, que a soberania dos brancos, "civilizados" dificulta o acesso das populações indígenas a certas tecnologias e avanços da modernidade, ao contrário do acesso dos brancos às aldeias, que é mais facilitado. Nessa direção, "o indivíduo se tornou um mero elo em uma enorme organização de coisas e poderes que arrancam de suas mãos todo o progresso, espiritualidade e valores, para transformá-los de sua forma subjetiva na forma de uma vida puramente objetiva.'” (SIMMEL, 1973, p. 23). Entende-se das palavras de Simmel uma utilização das pessoas, perdendo, mais uma vez, sua identidade própria, individual.

Além disso, Manoel Perna destaca a estrutura da sociedade, com a dificuldade de reconhecimento das relações genealógicas, já que os indivíduos escolhem os seus papéis:

Só os nativos do interior mantinham intacto aquilo que ele procurava: uma sociedade
em que, a despeito da rigidez das leis, os próprios indivíduos decidiam os seus papéis
dentro de uma estrutura fixa e de um repertório predeterminado. Havia um leque de
opções, embora restrito, e uma mobilidade interna. Foi o que ele me disse. Sempre
teve fascínio pelas ilhas. São universos isolados. (CARVALHO, 2006, p. 103)

Em todas essas narrações a respeito dos Krahô e dos Trumai, é possível perceber um elemento em comum: a ausência das vozes desses povos. Muito é dito sobre eles, mas em nenhum momento é dado a eles o poder de voz, da fala. Não é um momento sequer em que há inserção de fala das populações indígenas. Isso reforça o que foi mencionado anteriormente a respeito do silenciamento, que é uma consequência da ação conjunta da apropriação e da violência exercidas pelas camadas de maior poder socioeconômico e político. 


\section{Considerações finais}

Ao final desta análise, é possível constatar que os três romances possuem diversos pontos de convergência, sobretudo no que diz respeito à modernidade, compreendida, aqui, como geradora de exclusões e desigualdades. Na obra de Bernardo Carvalho, por exemplo, essa discussão é um pouco mais tímida, sem ter tanto destaque, voz, ao contrário do romance de Eça de Queirós, que coloca em discussão justamente a separação entre progresso, vinculado ao meio urbano, e o retrocesso, relacionado ainda ao campo.

A modernidade, com todas essas atribuições, dota-se de características e valores, muito bem representados nos romances, desde a exploração do trabalhador em $A$ selva, passando pelo silenciamento dos grupos indígenas em Nove Noites e até pelo embate entre campo e cidade, com diversos atravessamentos da sociedade materialista, dependente do dinheiro, desenvolvido por Eça.

Reconhecer a modernidade como uma visão de mundo e não como uma fase histórica é, portanto, admitir que ela está carregada de valores questionáveis e contrários ao antigo, perseguindo e se alimentando do que é novo, como se percebe em todos os três romances aqui analisados. 


\section{REFERÊNCIAS BIBLIOGRÁFICAS}

ABDALA JUNIOR, Benjamin. Necessidade e solidariedade nos estudos de literatura comparada. Revista Brasileira de Literatura Comparada, Uberlândia, v. 3, n. 3, p. 87-95, 1996.

CARVALHAL, Tânia Franco. Literatura Comparada. 4. ed. São Paulo: Ática, 2006.

CARVALHO, Bernardo. Nove noites. São Paulo: Companhia das Letras, 2006.

CASTRO, Ferreira de. A selva. 3. ed. Lisboa: Guimarães, 1945.

MARGATO, Izabel. Notas sobre o Neo-realismo português: um desejo de transformação. Via Atlântica. São Paulo: Universidade de São Paulo, 2009, p. 23-56.

PELLEGRINI, Tânia. Realismo: postura e método. Letras de Hoje, Porto Alegre, v. 42, n. 4, p. 137-155, 2007.

QUEIROZ, José Maria Eça de. A cidade e as serras. Porto Alegre: L\&PM, 2018.

SANTOS, Boaventura de Sousa. Para além do Pensamento Abissal: Das linhas globais a uma ecologia de saberes. Revista Crítica de Ciências Sociais, Coimbra, v. 78, 2007, p. 3-46. SIMMEL, Georg. A metrópole e a vida mental. In: VELHO, Otávio Guilherme. O fenômeno urbano. 2. ed. Rio de Janeiro: Zahar, 1973. 